\title{
BNCC e BNC da formação de professores: repensando a formação por competências
}

\author{
BNCC and BNC in teacher training: \\ rethinking training through competences
}

\section{La BNCC y la BNC de la formación de profesores: repensando la formación por competencias}

\section{ÂNGELA CRISTINA ALVES ALBINO*}

Universidade Federal da Paraíba, João Pessoa- PB. Brasil.

\author{
ANDRÉIA FERREIRA DA SILVA** \\ Universidade Federal de Campina Grande. Campina Grande- PB, Brasil.
}

\begin{abstract}
RESUMO: O presente estudo analisa a proposta de formação preconizada na Base Nacional Comum Curricular (BNCC) e na Base Nacional Comum para a Formação de Professores da Educação Básica (BNCFP), em sua versão preliminar de dezembro de 2018. Examina essas propostas, compreendo-as como marcadas por disputas em torno da definição de um projeto curricular para a educação no País. Questiona o viés pragmatista e reducionista na proposta de formação por competências. O texto resulta de revisão de bibliografia e da análise de documentos.

Palavras-chave: Docência. Formação. Currículo.
\end{abstract}

\begin{abstract}
The present study analyzes the proposition of qualification recommended in the National Curricular Common Core (BNCC) and in the National Common Core for the Teacher's Formation of Primary Education (BNCFP), in its preliminary version of December 2018. It examines these proposals, realizing them as set by disputes
\end{abstract}

* Professora da Universidade Federal da Paraíba - UFPB. Vice coordenadora do Grupo de Estudos e Pesquisas em Políticas Curriculares (GEPPC). Vice-diretora Estadual da Associação Nacional de Políticas e Administração da Educação (ANPAE).

* Professora da Universidade Federal de Campina Grande - UFCG. Coordenadora do Grupo de Pesquisa Avaliação Externa e Accountability na Educação Básica. Diretora Regional da Associação Nacional de Políticas e Administração escolar (ANPAE). 
over the definition of a curricular project for education in the country. It questions the pragmatist and reductionist bias in the proposal of training by competencies. The text results from bibliography review and document analysis.

Keywords: Teaching. Formation. Curriculum.

RESUMEN: El presente estudio analiza la propuesta de capacitación en la Base Nacional Común Curricular (BNCC) y en la Base Nacional Común para la Formación de Maestros de Educación Básica (BNCFP), en su versión preliminar de diciembre de 2018. El trabajo examina esas propuestas, entendiéndolas como marcadas por disputas sobre la definición de un proyecto curricular para la educación en el país, y cuestiona el sesgo pragmatista y reduccionista en la propuesta de formación por competencias. El texto resulta de la revisión de la literatura y el análisis de documentos.

Palabras clave: Docencia. Formación. Currículo.

\section{Introdução}

A s reformas neoliberais, no contexto de crise do capitalismo e formação para um mercado competitivo e de sustentação do capital, têm mobilizado processos de reformas curriculares em vários países. No Brasil, essa discussão (como em todo processo de decisão curricular) mobiliza interesses e provoca disputas em torno da definição de tipos e propostas de formação humana. Para compreendê-los, faz-se necessário conhecer, mesmo que rapidamente, o processo histórico de constituição da ideia de uma base nacional curricular, bem como as proposições contrárias a essa definição apresentadas por entidades progressistas da área da educação fundadas numa perspectiva da formação humana, tanto de discentes, quanto de docentes. Essas entidades constituíram-se em um grupo de resistência à proposta de uma base nacional curricular para a educação básica fundadas na visão pragmatista da formação por competências.

A Base Nacional Comum Curricular (BNCC) foi aprovada no dia 22 de dezembro de 2017, por meio da Resolução ${ }^{\circ} 2$ do Conselho Nacional de Educação - Conselho Pleno $(\mathrm{CNE} / \mathrm{CP})$, que institui e orienta sua implantação, a ser respeitada obrigatoriamente, ao longo das etapas e modalidades da educação básica. Apesar do texto se apresentar como conquista prevista em Lei, desde a Constituição Federal de 1988 e da Lei de Diretrizes e Bases da Educação Nacional (LDB), movimentos e associações do setor educacional se opuseram a sua aprovação. 
A proposta de BNCC começou a ser formulada ainda no governo Dilma, no primeiro semestre de 2015, com a participação de representantes de associações científicas de diversas áreas do conhecimento, de universidades públicas, do Conselho Nacional dos Secretários de Educação (Consed), da União Nacional do Dirigentes Municipais de Educação (Undime), bem como de representantes da classe empresarial, organizados no Movimento Pela Base Nacional Comum.

No processo histórico de formulação curricular, ao apresentar o relato de resistência à instituição da BNCC, AGUIAR (2018) destaca que, pelo Conselho Nacional de Educação (CNE), se consolidou a proposta de Base Nacional que não representava a concepção de Base Comum Nacional construída pelo movimento dos educadores ao longo das lutas, por uma educação cidadã. Temos, nesse percurso, disputas e tensões em torno de projeto de formação humana.

O texto da BNCC afirma que, "com a homologação da BNCC, as redes de ensino e escolas particulares terão diante de si, a tarefa de construir currículo, com base nas aprendizagens estabelecidas" (BRASIL, 2018a, p. 20). No entanto, essa tarefa conta com um texto previamente determinado nos detalhes a ser considerado de forma obrigatória, $\mathrm{o}$ que revela os limites das participação dos sujeitos escolares na construção do currículo.

O Ministério da Educação, no documento BNCC: educação é a base (BRASIL, 2018a), ao mesmo tempo que afirma que o currículo é tudo que é produzido na escola, instituiu uma normatividade que faz com que o texto formal/oficial tenha preponderância em relação aos saberes locais, que são apresentados como subcurriculares. Desse modo, institui uma relação hierárquica e a separação entre produção e implementação da BNCC e do currículo escolar, em geral.

O presente texto realiza, inicialmente, uma breve incursão na proposta de ensino/formação por competências presente nas políticas educacionais brasileiras, com mais força, a partir dos anos 1990. Em seguida apresenta a proposta formativa da BNCC (2017) e da Base Nacional Comum para a Formação dos Professores da Educação Básica (2018), refletindo acerca dos limites dessas propostas, questionando o caráter pragmatista e reducionista do currículo e da formação humana e, mais especificamente, da formação de professores nesse projeto.

\section{O modelo de formação por competências}

A compreensão do modelo de educação baseada em competência é polissêmica, tanto no Brasil como nos países em que se tornou preceito fundamental das instituições educativas. São muitas as matrizes epistêmicas. Como conceito, é construção social e revela os interesses de quem utiliza nas mais diversas políticas educativas pelo mundo. É no território de disputa curricular que conferimos sentido às formas de designar "o que os sujeitos precisam conhecer" e sob quais matizes. 
O modelo de educação pautada no ensino de competências não é algo eminentemente novo. Sacristan (2011, p. 7) entende que há uma facilidade em colocar em circulação por meio de "linguagens e metáforas que nos levam a denominar de forma aparentemente nova aquilo que, até então, reconhecíamos de outra forma". É o caso da educação por competências. Ele problematiza as várias compreensões da expressão: a) uma sociedade de indivíduos eficientes na engrenagem do sistema produtivo, b) movimento que enfoca a educação como adestramento, c) uma oportunidade de reestruturar os sistemas educacionais por dentro, superando o ensino centrado no conteúdo.

Nos EUA, esse conceito de educação baseada em competência surgiu na década de 60 a partir de questionamentos sobre a aprendizagem dos alunos e as habilidades necessária para a vivência fora da escola. Nesse mesmo período, é preciso entender a influência do behaviorismo nos objetivos pedagógicos, ao identificar o que seriam comportamentos adequados dos alunos.

Na Europa, o ensino por competências foi estimulado por políticas educacionais defendidas pela Organização das Nações Unidas para a Educação, Ciência e Cultura (Unesco) e Organização do Comércio e Desenvolvimento econômico (OCDE), bem como pela declaração de Bolonha, que consistiu em compromisso assinado por ministros da educação de dezenas de países para reformar o sistema de ensino superior.

O projeto Tuning Europa começou a ser desenvolvido a partir do ano 2000, a partir de um grupo de universidades chamado de "Processo de Bolonha", advindo da Declaração de Bolonha (1999), que consistiu em um acordo firmado por ministros da educação de diversos países da Europa para facilitar a mobilidade entre os países assinantes, bem como a garantia da qualidade do ensino com metodologias e critérios comparáveis. Assim, o objetivo era assegurar que o sistema superior de ensino europeu atraísse, pela vitalidade e eficiência, o olhar das demais nações sobre o seu sistema.

O modelo de competências na América Latina surge de forma mais evidente no processo de reformas educacionais, como parte das reformas estruturais do aparelho do Estado e todos os ajustes que esses países tiveram que fazer em seu ordenamento macroeconômico nos anos de 1990. Era meta resolver o problema da inflação e retomar o crescimento econômico da década anterior a partir de estabilização econômica e equilíbrio, implicando em cortes e gastos públicos, flexibilização do trabalho, reforma de previdência social e privatizações.

No Brasil, sobretudo a partir dos anos de 1990, podemos identificar a influência e adesão à concepção de formação por competências em alguns documentos curriculares, a exemplo da Diretrizes Curriculares Nacionais Gerais da Educação Básica (1999). Segundo Ricardo (2010, p. 10), o modelo vai pleitear uma formação do homem como recurso humano e não como sujeito, o que lhe confere a feição de um "objeto do capital moderno". A formação por competências visa a preparação do homem para atender às condições contemporâneas de produção de bens e serviços em suas novas formas de organização do trabalho. 
Nesse processo histórico, é importante compreender quais os desdobramentos do modelo de educação por competências que a BNCC (2017) enseja, quando pensamos no aluno de educação básica no Brasil. Que lógicas de implementação da política curricular podem contribuir ou não para o aprofundamento das desigualdades educacionais? Como pensar a lógica das competências a partir de um ideal de formação humana mais cidadã e menos mercadológica?

\section{A Formação discente na Base Nacional Comum Curricular}

A formação humana na BNCC é costurada por uma dimensão humana e jurídica do direito de aprender, bem como fundamentada na educação baseada em competências. É uma política de currículo baseada em experiências internacionais e justificada também por essas experiências. É importante salientar que nenhum documento curricular possui pureza epistemológica ou está ausente de processos de lutas e múltiplas colagens; ele é interdiscursivo e intertextual. Nesse sentido, a BNCC traz marcas ideológicas, tensões e diferenças, negadas em seu processo de construção.

O texto de apresentação da Base a define como "um documento de caráter normativo que define o conjunto orgânico e progressivo de aprendizagens essenciais" (BRASIL, 2018a, p. 7). A perspectiva de normatização do currículo é anunciada com o viés essencialista, muito debatido entre os estudos curriculares de Macedo (2014), Süssekind (2014) e Lopes (2015). A aprendizagem é apresentada de forma massificada, com a descrição detalhada de "tudo" o que todos os alunos devem desenvolver ao longo da educação básica. Nessa perspectiva, a diferença, sobretudo quando tratamos de políticas de inclusão/deficiência, fica descaracterizada e inferiorizada.

No Brasil, alguns documentos curriculares já contemplaram os conceitos de habilidades e competências a exemplo dos Parâmetros Curriculares Nacionais (PCN) (BRASIL 1997), Parâmetros Curriculares Nacionais do Ensino Médio (PCNEM) (BRASIL, 2000), bem como os sistemas de avaliações nacionais como Sistema de Avaliação da Educação Básica (SAEB/BRASIL, 2008) e Provinha Brasil (BRASIL, 2011). No entanto, o retorno ao modelo curricular por competências é visto com preocupação, por se consubstanciar em uma perspectiva reducionista do conhecimento a esquemas e modelos, em detrimento de um modo processual de compreensão curricular.

A BNCC é definida como "um documento de caráter normativo que define o conjunto orgânico e progressivo de aprendizagens essenciais que todos os alunos devem desenvolver ao longo das etapas e modalidades da Educação Básica" (BRASIL, 2018a, p. 7). A Base se constitui como referência nacional obrigatória para a elaboração dos currículos municipais, estaduais, do Distrito Federal. É parte integrante da política nacional de educação básica e objetiva alinhar-se a outras políticas como formação docente, avaliação 
e infraestrutura básica para desenvolvimento educacional em todo território nacional. Busca um "patamar" comum de aprendizagens para todos os estudantes a partir de dez competências gerais (BRASIL, 2018a).

A noção de competência, na BNCC (2018a), é compreendida como: “a mobilização de conhecimentos (conceitos e procedimentos), habilidades (práticas, cognitivas e socioemocionais), atitudes e valores para resolver demandas complexas da vida cotidiana, do pleno exercício da cidadania e do mundo do trabalho". A essa compreensão, deve ser acrescentada, ainda, a vinculada à preservação da natureza, a partir das demandas da Agenda 2030 da Organização das Nações Unidas (ONU).

No processo de definição da BNCC, enquanto referente nacional, a apropriação de propostas oriundas de entidades progressistas do campo da educação vai, em certa medida, contribuir para a definição do texto final da BNCC, como resultado das disputas em torno de diferentes perspectivas da produção de conhecimento. Ao definir os fundamentos pedagógicos da formação, a BNCC (2018a, p. 13) define como foco o desenvolvimento de competências como proposta marcante das últimas décadas que tem orientado os currículos em diferentes países.

Nessa perspectiva, a formação humana é subalternizada a partir de uma série de condicionantes, sobretudo de ordem internacional. O currículo pautado nos fundamentos pedagógicos das competências é configurado como necessário não por uma necessidade nacional de pensar a formação humana integral, mas como resposta à uma demanda mundial. $\mathrm{O}$ texto parte da exterioridade para justificar a qualidade dos processos de aprendizagem; na própria descrição inicial, a potência discursiva não evidencia o pluralismo e as próprias condições da escola brasileira e nem mesmo um breve perfil de quem são os discentes para quem foi elaborada a proposição curricular. As respostas clássicas do currículo não são contempladas nessa descrição: para quem se destina esse conjunto de habilidades e competências? Quem é esse aluno brasileiro que será mediado por saberes "comuns"?

Os textos curriculares podem, também, promover exclusões, que acabam por assumir força na prática social dos discentes. De toda forma, é importante destacar a função das instituições escolares como espaço de denúncia e resistência aos discursos e práticas que vão legitimar a marginalização (SACRISTÁN, 2013). Nesse sentido, entendemos que o currículo no formato da BNCC pode ser um reforçador de desigualdades, quando parte de uma lógica de formação humana, sobretudo pensada a partir de "evidências internacionais".

As experiências sociais e culturais assumem um percentual na proporção de definição do currículo (40\% local para $60 \%$ nacional), que deve ser pensado pelos estados e municípios. O texto da BNCC pouco contemplou as vozes discentes e as experiências concretas já desenvolvidas nas escolas brasileiras. Os conhecimentos, habilidades 
e competências a serem ensinados para os alunos brasileiros foram estabelecidos sem a participação efetiva dos maiores interessados. A representação estudantil nas Conferências de elaboração da Base foi pífia. Esse modo de segregação nos leva a crer que, de fato, os currículos nacionais ainda não conseguem dialogar com os pobres e sua pobreza (ARROYO, 2015).

A BNCC (2018, p. 6) evidencia que irá "garantir o conjunto de aprendizagens essenciais aos estudantes brasileiros, seu desenvolvimento integral por meio das dez competências gerais para a Educação Básica". As dez competências são amplas e contemplam muitos encaminhamentos definidos nas DCN (2013) em torno da formação discente. Nesse contexto, é importante defender o caráter geral das DCN, por respeitar a autonomia dos estabelecimentos de ensino e dos professores em definir a partir de sua realidade os objetivos e programação de aprendizagem. A BNCC tem uma estrutura discricionária e invasiva do trabalho docente. É evidente a compreensão de manual detalhado em torno das competências e habilidades, subposicionando o professor a um executor de tarefas pedagógicas.

O texto da BNCC (2018, p.06) destaca a incapacidade do documento para alterar, "por si só", o quadro de desigualdade, mas a posiciona como "essencial", pois irá influenciar a "formação inicial e continuada de educadores, a produção de materiais didáticos, as matrizes de avaliação e os exames nacionais". As expectativas de aprendizagem descritas em detalhe pelo documento assumem a grande função de que, caso seja acompanhado pela sociedade, a partir do regime de colaboração, faça o país avançar. O princípio da objetividade parece ter força para a redução das desigualdades educacionais, ou seja, éramos atrasados porque não tínhamos uma descrição de competências a serem alcançadas pelos alunos.

A perspectiva de formação humana nas $\operatorname{DCN}(2013$, p. 185) traz uma ideia de organicidade e do trabalho como princípio educativo. "(...) o trabalho como primeira mediação entre o homem e a natureza" e de suas relações com a sociedade" e com cada uma das outras dimensões curriculares reiteradamente mencionadas. $O$ trabalho é sugerido a partir de uma dimensão problemática e relacional e um constante chamado a "olhar as situações reais existentes nas práticas sociais" dos discentes. O trabalho assume a dimensão primeira entre o humano e o meio ambiente na produção social e histórico-cultural dos grupos.

O comum na BNCC (2018) é o todo objetivado e descrito em ações, conteúdos, habilidades e competências, enquanto que nas DCN (2013) o comum são princípios gerais norteadores da prática pedagógica a partir dos seus contextos sociais. O argumento da incapacidade docente de delimitar e objetivar a sua ação não serve como justificativa para limitar as escolas e os discentes a inquiridos da instrução. A ação desses sujeitos é criativa e sua autonomia precisa ser preservada para a (re)criação do movimento de aprendizagem social, que, existencialmente, faça sentido e contribua para sua emancipação. 
Os processos formativos numa perspectiva de orientação humana, autônoma e crítica podem ser suprimidos quando a excessiva categorização e descrição de uma base normatizante passa a reduzir a produção de conhecimento a um sequenciamento esquemático de descritores. O sentimento de pertença faz parte de uma educação e produção de conhecimento a partir da estrutura democrática. Sem essa participação efetiva (sobre: o que conhecer? Para que conhecer? Por que conhecer? Por que esses conhecimentos e não outros?) a compreensão de conhecimento fica reduzida e mecânica, o que contribui para a conformação e menos justiça cognitiva, como lembra Santos (2010); e, portanto, menos justiça social. Para ele, "diferentes objetivos necessitam de diferentes conhecimentos" e cita como exemplo: "Se eu quiser ir à lua preciso do conhecimento científico, mas se quiser saber sobre um rio, posso ter o conhecimento dos indígenas". O direito à memória e à história aparecem como fundamentais para vencer a luta contra o colonialismo e o patriarcado.

Nessa direção é oportuno problematizar, também, a partir da Base Nacional Comum para Formação Docente (BNC FP, 2018), as questões relativas às demandas necessárias para a produção de conhecimento democraticamente construído e socialmente útil. O texto da BNCC (2018, p.22) deixa explícito que será responsabilidade da União “a formação inicial e continuada de professores para alinhá-las à perspectiva da base discente", uma vez que compete a essa esfera a regulação do ensino superior, no qual se formam os docentes.

\section{A BNC para a Formação de Professores da Educação Básica (2018)}

Em dezembro de 2018, o Ministério da Educação divulgou versão preliminar da Base Nacional Comum da Formação de Professores da Educação Básica. Tal proposta, apresentada no Governo do Presidente Temer, retoma, em grande medida, princípios e medidas contidas na Resolução n⿳o 1 , de 18 de fevereiro de 2002, do Conselho Pleno do $\mathrm{CNE}$, que estabeleceu as Diretrizes Curriculares Nacionais para a Formação de Professores da Educação Básica, em nível superior, curso de Licenciatura, Graduação Plena, aprovada ainda no Governo do Presidente Fernando Henrique Cardoso, que teve vigência até 2015. O documento reafirma a formação docente por competência, a necessidade da intensificação dos vínculos entre as instituições formadoras e a realidade escolar desde o início dos cursos de formação e a implementação de um sistema de avaliação de cursos e de certificação competências dos docentes (SILVA, 2019).

A Resolução CP/CNE nํㅜ 1/2002 foi revogada somente em 2015, pela Resolução nº 2, de $1^{\circ}$ de julho de 2015, que passou a normatizar as Diretrizes Curriculares Nacionais para a formação inicial em nível superior (cursos de licenciatura, cursos de formação pedagógica para graduados e cursos de segunda licenciatura) e para a formação continuada, a despeito das críticas apontadas pelas entidades acadêmicas e científicas da área da educação. 
A Resolução CP/CNE nº 1/2002 estabelece que a formação de professores para as diferentes etapas e modalidades da educação básica deveria ter a "competência como concepção nuclear na orientação do curso" (BRASIL, 2002, art. 3º, inciso I). Também, prescreve, no artigo $4^{\circ}$, que na concepção, no desenvolvimento e na abrangência dos cursos de formação de professores deverá ser considerado o conjunto das competências necessárias à atuação profissional e que as competências deverão nortear, "tanto da proposta pedagógica, em especial do currículo e da avaliação, quanto da organização institucional e da gestão da escola de formação" (art. 3ํㅡㄹ inciso I e II) ${ }^{1}$. Estabelece as seis competências que deveriam ser alcançadas na formação docente (Art. 6). Além de prever, no artigo 16, a organização de um sistema federativo de certificação de competência dos professores da educação básica.

De acordo com Silva (2019), a proposta de formação por competências e da criação de um sistema de certificação dos professores da educação objetiva a superação do modelo de formação pautado na qualificação profissional, centrado em títulos e diplomas que atestariam o domínio de conceitos técnico-científicos, para o da formação por competências² que teriam que ser adquiridas, validadas e constantemente atualizadas para garantir a empregabilidade do trabalhador e a adequação de seu trabalho às demandas de uma sociedade em constante transformação. Desse modo, a criação de um sistema nacional de certificação de competências para os professores, pautado em competências e habilidades previamente definidas, visava a extensão do modelo adotado para a formação profissional para a preparação dos docentes. É importante afirmar que a aprovação da BNCC, em 2017, estende para a educação básica essa concepção.

A aprovação das Diretrizes para a Formação de Professores, pela Resolução n⿳o 1/2002, fez emergir inúmeros questionamentos dos segmentos organizados do campo da educação, sobretudo, das entidades científicas e acadêmicas. Anped, Anfope, Anpae, Forumdir e o Fórum Nacional em Defesa da Formação do Professor ${ }^{3}$ 'que se manifestaram contrariamente à Resolução e reafirmaram, entre outros, a base comum nacional para os cursos de formação de professores como garantia de unidade para a multiplicação de experiências curriculares, sem prejuízo do reconhecimento das IES e dos currículos dos estudantes.

Para compreender a retomada do projeto de formação por competência, de avaliação e de certificação dos docentes, em dezembro de 2018, é preciso referir-se ao Golpe jurídico-institucional, que levou ao impeachment da presidente Dilma Rousseff, em 31 de agosto de 2016. Entre os partidos que realizaram e apoiaram o golpe, o Partido da Social Democracia Brasileira (PSDB) teve grande participação $0^{4}$. Como resultado, dessa atuação, o PSDB ocupou cargos importantes no Governo de Michel Temer, entre eles, no Ministério da Educação. Tal situação, conduziu novamente ao MEC profissionais que tinham atuado na definição das políticas de formação do Governo de FHC, como as professoras Guiomar Namo de Mello e Maria Helena Guimarães Castro. Nesse contexto, foram retomadas, com prioridade, propostas implantadas no governo do PSDB. 
A despeito de ter sido aprovada em 2001 e ter tido 14 anos de vigência, durante quase todo o período do PT na Presidência da República, as Diretrizes para a Formação de Professores para a Educação Básica, definidas na Resolução n⿳ำ 1/2002, parecem não ter sido amplamente incorporadas aos projetos pedagógicos dos cursos de formação dos docentes, sobretudo nos cursos de Pedagogia, em decorrência, dentre outros, das críticas apontadas a essa proposta. Tal análise, consta da versão preliminar da Base Nacional da Formação de Professores do Governo Temer, quando o documento afirma que a

\begin{abstract}
elaboração de DCNs para as licenciaturas, inclusive as de Pedagogia foram elaboradas ignorando o Parecer 09/2001 do plano do CNE bem como a Resolução 01/2002 que nele teve origem. Apenas algumas licenciaturas se apropriaram desses dois marcos legais gerais e desenvolveram DCNs próprias de forma harmoniosa com os mesmos (BRASIL, 2018, p. 16).
\end{abstract}

A proposta da Base Nacional Comum, apresentada em dezembro de 2018, no final do Governo Temer, consiste, em grande medida, na reafirmação e na atualização de princípios e estratégias constantes da Resolução n $1 / 2002$ e na assimilação de estratégias constantes nas Metas 13, 15, 16 e 18, do PNE (2014-2024), relativas a instrumentos de avaliação e processos de certificação e admissão de cursos de professores (BRASIL, 2014). Desse modo, visa a possibilitar a implantação das concepções norteadoras dessa Resolução, a despeito das críticas recebidas e de sua revogação em 2015, e de definições do PNE em vigência. Dessa vez, assimilando e ressignificando um princípio fundamental defendido pelos movimentos da área da educação para a formação de professores, a proposta de uma base comum nacional para a formação de professores ${ }^{5}$. Observa-se que as Diretrizes de 2002 foram transformadas em proposta de base nacional comum, convertendo-a, de fato, na Base Nacional Comum Curricular para a Formação de Professores (BNCC-FP), como, inclusive, foi noticiado por alguns veículos de comunicação.

A proposta da Base Nacional Comum tem por objetivo adequar a formação de professores à BNCC, no entanto, a unidade entre estes documentos já está assegurada, visto que estão ancorados na perspectiva da formação por competências. De acordo com o documento "[...] a BNCC deverá ser, daqui em diante, uma referência para a formação inicial e continuada dos professores. Abre-se assim uma janela de oportunidade para debater alguns dos entraves e dar qualidade à formação do professor brasileiro" (BRASIL, 2018b, p. 7). Tal alinhamento está pre-

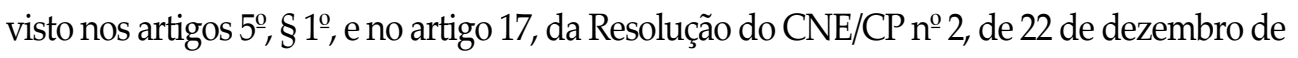
2017, que instituiu a BNCC.

A propostaéjustificada pelos baixos resultados das escolas brasileiras nos exames nacionais e internacionais, a baixa qualidade da formação docente, a importância da atuação do professor na determinação do desempenho dos alunos e a necessidade da implantação da BNCC. As principais mudanças contidas na versão preliminar da Base Nacional Comum da Formação de Professores (2018b) referem-se à formação inicial e continuada, à instituição de instrumentos e instâncias de avaliação e de certificação dos docentes e uma proposta de curso de Pedagogia. 
No que se refere à formação inicial, são apresentadas propostas referentes aos princípios que devem orientar a formação, ao estágio supervisionado e ao Exame Nacional de Cursos (Enade). De acordo com a proposta, a formação de docentes deverá sustentar-se nos seguintes princípios: visão sistêmica da formação de professores, que deve articular formação inicial, continuada e carreira; colaboração entre instituições formadoras, redes de ensino e escolas de educação básica; formação com foco na prática de sala de aula; importância do conhecimento pedagógico do conteúdo; e formação integral do professor - competências, habilidades e valores (BRASIL, 2018b).

Para a viabilização desses princípios são propostas duas medidas. A primeira, a substituição da realização do estágio curricular pela residência pedagógica, desde o primeiro semestre do curso. Desse modo, a prática profissional estaria fazendo parte da formação inicial. Nessa proposta, as instituições formadoras, faculdades, centros ou núcleos deveriam estar associados ou conveniados com uma ou mais escolas de educação básica para a efetivação da residência pedagógica (BRASIL, 2018). A segunda medida, a aplicação anual do Enade para as licenciaturas, adequado à nova matriz de competências proposta na Base. Esse Exame passaria a ser obrigatório e poderia servir como habilitação à docência e, também, ao ingresso na carreira, com validade de cinco anos. O documento propõe que "todos os alunos podem fazer o exame durante a graduação ou depois dela e se habilitar à docência no caso de aprovação" (BRASIL, 2018, p. 35). Pelo exposto, os licenciandos aprovados no Enade já estariam habilitados para a docência.

No que se refere à formação continuada, são articulados mecanismos de avaliação do professor e de ascensão na carreira. A proposta reconhece que compete ao Governo Federal definir os marcos regulatórios e zelar pela oferta da educação superior, incluindo os cursos de formação de professores de instituições públicas e privadas. Destaca, ainda, a importância da articulação entre os entes federados e instituições formadoras para o avanço de uma política comum para o desenvolvimento da formação inicial e continuada de professores da educação básica. No entanto, afirma que o fortalecimento das iniciativas de formação continuada incide diretamente nas secretarias estaduais, distrital e municipais de educação. Pelo exposto, as iniciativas de formação continuada estariam sob a responsabilidade das secretarias estaduais e municipais de educação, apontando para a redução do papel do Governo Federal nesse setor.

O documento propõe que, após o ingresso no magistério, o docente iniciante deverá contar com o apoio de um mentor, que deverá ser um professor mais experiente, e que oriente, acompanhe e auxilie o ingressante nas atividades docentes (BRASIL, 2018). O professor mentor poderá receber uma gratificação pelo exercício dessa função.

De acordo como documento, a formação continuada deve estar atrelada à evolução funcional ao longo da carreira do docente. Nessa perspectiva, o docente adquirirá no exercício profissional novas competências e habilidades, que poderão ser comprovadas por meio de avaliações, titulação e desempenho. A matriz de competência 
poderá ser utilizada como parâmetro para o exame dos professores. Segundo a versão preliminar da Base,

Da mesma forma que a formação, a carreira do professor se articula à Base Nacional de Formação. [...] As competências auxiliam na construção de uma trajetória profissional que envolve aspectos relativos ao desenvolvimento e à avaliação de desempenho, fundamentais para a qualidade do trabalho docente (BRASIL, 2018, p. 40).

Para a materialização dessa proposta, o documento propõe a criação de um instituto nacional de acreditação e formação de profissionais da educação básica, visando a formulação de políticas de avaliação, a coordenação e o monitoramento da definição de competências e das ações de certificação de cursos e docentes.

Em relação à Matriz de Competências constitutivas da Base, o documento elenca três dimensões que fazem parte da competência profissional dos professores: conhecimento profissional, prática profissional e engajamento profissional. Cada uma dessas competências se desdobra em quatro competências específicas.

A divulgação da versão preliminar da Base Nacional Comum para a Formação de Professores fez emergir manifestações imediatas das entidades organizadas da área da educação. A Anfope e o Forumdir elaboraram um "Manifesto em defesa da formação de professores", em que manifestaram posição contrária à proposta e denunciaram seu caráter impositivo e autoritário, que não buscou estabelecer o necessário diálogo com os principais atores da formação de professores. Apontam, também, o retrocesso da proposta, em decorrência da fragmentação da formação e a da retomada de concepções ultrapassadas, orientadas pela noção de competências e habilidades. Indicam que tal projeto está marcado pela lógica da reforma empresarial que a orienta, como a instituição de avaliações e certificação para o ingresso e progressão na carreira.

No Manifesto, Anfope e Forumdir afirmam que as proposições apresentadas na Base

\begin{abstract}
expressam a intenção de desmonte dos cursos de formação de professores em nível superior e o aprofundamento do processo de desprofissionalização da carreira docente, ao assumir uma visão "praticista" da docência, que tende a padronização curricular e fere a autonomia das universidades, desconsiderando os projetos curriculares dos cursos, os alinhando à Base Nacional Comum Curricular, cujo processo de elaboração, discussão e aprovação também foi marcado pelo autoritarismo e simulação de diálogo (ANFOPE; FORUMDIR, 2018).
\end{abstract}

Em relação à proposta de criação de um instituto nacional de acreditação e de formação de professores, o Manifesto afirma que isso consiste em uma "forma de ampliar o controle sobre as instituições ferindo a autonomia universitária e comprometendo a diversidade de projetos de formação" (ANFOPE; FORUMDIR, 2018). 
O Manifesto da Anfope e Forumdir questionou, ainda, a visão "tarefeira, reduzida e alienada da docência presente no documento". Destacou, também, a ausência, na proposta de Base Nacional Comum, de dois princípios, constitutivos da base comum nacional, que historicamente vem sendo defendido pelo movimento:

(1) a sólida formação teórica e interdisciplinar sobre o fenômeno educacional e seus fundamentos históricos, políticos e sociais, que não podem ser dissociados do domínio dos conteúdos da educação básica, se ensejamos criar condições para o exercício da análise crítica da sociedade brasileira e da realidade educacional; e (2) a unidade teoria-prática atravessando todo o curso de modo a garantir o trabalho como princípio educativo na formação profissional (ANFOPE; FORUMDIR, 2018).

No dia 21/12/2018, oito entidades acadêmicas e científicas nacionais também lançaram documento, posicionando-se diante da proposta de Base Nacional Comum da Formação de Professores. O documento, "Nota sobre a Base Nacional Comum para Formação de Professores", denuncia que, "no apagar das luzes, o MEC mais uma vez coloca unilateralmente em destaque um novo documento sem qualquer consulta à comunidade escolar, aos pesquisadores, às escolas e às universidades" (ANPEd et al, 2018). Questiona a proposta por retomar a fragmentação do curso de Pedagogia depois do esforço para a construção de uma perspectiva unitária da formação. Afirma que a apresentação de uma proposta de Base Nacional para Formação de Professores consistiria em uma forma de não enfrentar os problemas reais da educação brasileira. $\mathrm{O}$ documento é finalizado conclamando o CNE para retomar o diálogo com a comunidade educacional brasileira e realizar a discussão da proposta.

Nos dois manifestos, os movimentos da área da educação criticaram, mais uma vez, a proposta de formação por competências e a instituição de um sistema de sua certificação, bem como o projeto de alinhamento da formação de professores à BNCC. Defenderam a manutenção das Diretrizes Curriculares Nacionais para a formação inicial em nível superior (cursos de licenciatura, cursos de formação pedagógica para graduados e cursos de segunda licenciatura) e para a formação continuada, Parecer CNE/CP n. 2, de 9/6/2015 e Resolução CNE/CP n. 2, de 1/7/2015, que expressariam os proposições do movimento dos educadores.

No dia 19/01/2019, início do Governo do presidente Bolsonaro, o Ministério da Educação decidiu conhecer a versão preliminar da Base Nacional Comum da Formação para Professores. O Ministério informou, em nota, querer ter ciência e participar ativamente do processo de formulação da Base e que após a análise do documento decidirá se fará modificações. Até o momento, não há novas informações sobre a elaboração da Base. A primeira reunião da Comissão do CNE encarregada de analisar a proposta, Comissão da BNC, estava agendada para 20/01/2019. A previsão para a aprovação da Resolução da BNC era até o fim de 2019. No novo governo ainda não há previsão. 


\section{Considerações finais}

No contexto atual, uma Base de formação discente/docente ocupa lugar de receituário para solução dos problemas educacionais no Brasil. As razões econômicas disfarçadas de uma linguagem técnica e científica configuram a necessidade de reformulação da política educativa na perspectiva de qualidade, a partir de modulação de aprendizagem via controle e avaliação.

O retorno a um modelo de formação por competências no contexto de produção de Base para formação discente e docente no Brasil insiste na lógica de produção de saberes pelo caminho objetivista em que, alunos e professores são pensados como receptores de modelos educacionais pensados por "especialistas". O texto da BNCC $(2018$, p.14) para formação discente é justificado pelas exigências da OCDE e de avaliações como Pisa. A OCDE é uma das grandes propositoras da educação baseada em competências com fornecimento de modelos de manuais e estratégias de avaliação. Como se vê, o currículo é perspectivado em um modelo de organização corporativa para atender ao mercado em que as ciências humanas são suprimidas/marginalizadas, no rol de saberes "importantes". A boa formação parece apontar para aquela que o sujeito "sabe fazer".

O percurso histórico de condução das bases comuns de formação é indicativo de descaracterização da docência e da discência. Modelos constitutivos de pseudodemocracia com uma compreensão limitada de participação, ao mesmo tempo, se configuram como referentes "essenciais". O saber fazer, operar e praticar conceitos são elementos constitutivos dos processos formativos nas bases de formação (BNCC, 2018, BNC FP, 2018).

O manifesto da Anfope e Forumdir é esclarecedor quanto à visão "tarefeira" de percepção da docência na Base Nacional de Formação de Professores, o que contraria os princípios que consideram constitutivos destes movimentos, quais sejam: formação teórica e interdisciplinar sobre o fenômeno educacional, bem como unidade teoria-prática e o trabalho como princípio educativo. Esses fundamentos já foram referendados nas DCN (2013), quando descreviam o tipo de formação de homem priorizado no processo de produção do conhecimento.

Por fim, na lógica do receituário pragmatista que incide sobre as políticas curriculares no Brasil, o período que consubstancia a formulação das "bases", acaba por enfraquecer a ideia de fortalecer os projetos político-pedagógicos das escolas (Art. 12/ LDB, 1996) como proposição identitária, plural e de feição democrática. Os sujeitos nessa compreensão são entendidos como protagonistas e profissionais do processo de produção do conhecimento. A autonomia se faz fundamento nesse percurso formativo.

Recebido em: 21/05/2019 e aprovado em: 01/06/2019 


\section{Notas}

1 As Diretrizes da formação de professores, de 2002, possui três princípios que deveriam definir a formação de professores. O primeiro se refere à noção de competência como concepção nuclear do curso. O segundo, à garantia da coerência entre a formação oferecida e a prática esperada do futuro professor, considerada possível se o seu preparo ocorresse em lugar similar ao qual iria atuar, ou seja, para que esta coerência fosse alcançada seria preciso possibilitar a coerência entre o que o futuro professor faz na formação e o que dele se esperaria na atuação profissional. O terceiro princípio consiste na afirmação da pesquisa como elemento essencial, com foco no processo de ensino aprendizagem (SILVA, 2019).

2 No que se refere às relações entre o conceito de qualificação e o de competência, Ramos (2001) esclarece que a noção de competência reafirma e nega ao mesmo tempo o conceito de qualificação. Deste modo, no conceito de competência há um deslocamento conceitual em relação ao conceito de qualificação e não a sua negação. Neste sentido, explica Ramos (2001), "A reafirmação [do conceito de qualificação] ocorre pelo fato de os novos processos de produção demandarem do trabalhador não somente conhecimento técnico, mas também, e fundamentalmente, que seus atributos subjetivos sejam postos em jogo na realização das atividades profissionais. Assim, a dimensão experimental da qualificação, que faria apelo à subjetividade do trabalhador e que teria sido pouco considerada nas análises dos processos de trabalho e na própria construção do conceito, finalmente tomaria seu lugar de destaque. A noção de competência expressaria coerentemente essa dimensão, pois seu significado psicológico chamaria atenção para as capacidades cognitivas e sócio-afetivas também mobilizadas pelos trabalhadores na realização de suas atividades profissionais." (p. 281).

3 O Fórum em Defesa da Formação de Professores foi criado em 1999, com o objetivo de articular as discussões e a organização contra a política autoritária de formação de professores do Governo $\mathrm{FHC}$, materializada no Decreto no 3.276/1999, que estabeleceu que a formação em nível superior de professores para a atuação multidisciplinar, destinada ao magistério na educação infantil e nos anos iniciais do ensino fundamental, deveria ocorrer exclusivamente em cursos normais superiores. Foi alterado pelo Decreto $\mathrm{n}^{\mathrm{o}}$ 3.554/2000, que substituiu a expressão "exclusivamente" do decreto por "preferencialmente", retirando o caráter de obrigatoriedade. Foi constituído pelas seguintes as entidades: Andes-SN, Anfope, Anped, Anpae, Associação Brasileira de Tecnologia Educacional (ABT), Cedes, Comissão de Especialistas do Curso de Pedagogia, Forumdir, Fórum Paulista de Educação Infantil, Fórum Paulista de Pedagogia e Fórum Nacional em Defesa da Escola Pública (SILVA, 2019).

4 Para uma análise bem fundamentada do Golpe jurídico-institucional ocorrido no Brasil, em 2016, da participação do PSDB e de seus desdobramentos e desafios para o setor da educação, ler Souza (2017).

5 De acordo com Scheibe e Bazzo (2001), a expressão “base comum nacional” foi cunhada pelo Movimento Nacional de Formação do Educação, no início da década de 1980, num contexto de lutas pela redemocratização da sociedade brasileira. Segundo Silva (2019), naquele momento, a Comissão Nacional pela Reformulação da Formação do Professor, antecedente histórica da Anfope, propunha que "todas as licenciaturas (Pedagogia e demais áreas) deveriam ter uma base comum, pois dedicam-se a formar professores a docência constituiria a base da identidade profissional de todo educador. A base comum nacional dos Cursos de Formação de Educadores não deveria ser concebida como um currículo mínimo ou um elenco de disciplinas, mas como uma concepção básica da formação do educador e a definição de um corpo de conhecimento fundamental. A proposta de base comum nacional deveria contemplar: disciplinas relativas ao conteúdo específico; disciplinas relativas à formação pedagógica; disciplinas integradoras (SILVA, 2019, p. 76). 


\section{Referências}

AGUIAR, M. A. da S. Relato da resistência à instituição da BNCC pelo Conselho Nacional de Educação mediante pedido de vista e declarações de votos. In: AGUIAR, Márcia Ângela da S.; DOURADO, Luís Fernandes. (Orgs). A BNCC na contramão do PNE 2014-2024: avaliação e perspectivas. [Livro Eletrônico]. Recife: ANPAE, 2018.

ASSOCIAÇÃO NACIONAL PELA FORMAÇÃO DOS PROFISSIONAIS DA EDUCAÇÃO (ANFOPE); FORUM NACIONAL DE DIRETORES DE FACULDADES/CENTROS/ DEPARTAMENTOS DE EDUCAÇÃO OU EQUIVALENTES DAS UNIVERSIDADES PÚBLICAS BRASILEIRAS (FORUMDIR). Manifesto em defesa da formação de professores. 14/12/2018. 2018. Disponível em: http://www. anfope.org.br/wp-content/uploads/2018/12/NOTA_FORMA\%C3\%87\%C3\%83O_PROFESSORESAnfope-Forumdir.pdf Acesso em: 10 abr. 2019.

ASSOCIAÇÃO NACIONAL DE PÓS-GRADUAÇÃO E PESQUISA EM EDUCAÇÃO (ANPEd) et al. Nota sobre a Base Nacional Comum para Formação de Professores. 21/12/2018. 2018. Disponível em: http://www.anped.org.br/news/nota-sobre-base-nacional-comum-para-formacao-de-professores. Acesso em: 10 abr. 2019.

ARROYO, M. G. Pobreza e currículo: uma complexa articulação. Brasília: MEC, 2015.

BRASIL. Parâmetros Curriculares Nacionais: ensino médio. Brasília: Semtec, 1999.

BRASIL. Ministério da Educação. Base Nacional Comum Curricular (BNCC). Educação é a base. Brasília. 2018a. Disponível em: 568 http://basenacionalcomum.mec.gov.br/images/BNCC_publicacao. pdf. Acesso em: 02 maio 2018.

BRASIL. Ministério da Educação. Proposta para Base Nacional Comum da Formação de Professores da Educação Básica. 2018b.

BRASIL. Lei no . 13.005, de 25 de junho de 2014 que aprova o Plano Nacional de Educação (2014-2024). Disponível em: http://www.planalto.gov.br/ccivil_03/_ato2011-2014/2014/lei/113005.htm. Acesso em: 30 abr. 2018.

BRASIL. Ministério da Educação. Secretaria de Educação

Básica. Diretrizes Curriculares Nacionais Gerais da Educação

Básica. Brasília, 2013.

GIMENO SACRISTÁN, José; PÉREZ GÓMEZ, Ángel I.; MARTÍNEZ RODRÍGUEZ, Juán B.; TORRES SANTOMÉ, Jurjo; ÂNGULO RASCO, Félix; ÁLVAREZ MÉNDEZ, Juán M. Educar por Competências. O que há de novo? Artmed, 2011.

LOPES, A. C. Por um currículo sem fundamentos. Linhas Críticas, Brasília, v. 21, p. 445- 466, 2015.

MACEDO, E. Base Nacional Curricular Comum: novas formas de sociabilidade produzindo sentidos para educação. Revista E-Curriculum, São Paulo, v.2, n.3, p.1530-1555, out./dez., 2014.

MACEDO, E. Currículo como espaço-tempo de fronteira cultural. Revista Brasileira de Educação, v. 11, n. 32. maio/ago. 2006.

RAMOS, Marize Nogueira. A pedagogia das competências: autonomia ou adaptação? São Paulo: Cortez, 2001.

RICARDO, Elio Carlos. Discussão acerca do ensino por competências: problemas e desafios. Cadernos de Pesquisa. São Paulo, v. 40, n. 140, p. 605-628, maio/ago. 2010. 
SANTOS, B. S. Para além do pensamento abissal: das linhas globais a uma ecologia dos saberes. In: SANTOS, B. S.; MENESES, M. P. Epistemologias do Sul. São Paulo: Cortez, 2010.

SCHEIBE, Leda; BAZZO, Vera Lúcia. A construção de uma base comum nacional para a formação de profissionais da educação no Brasil. Contrapontos. Revista de Educação da Univali. ano 1, n. 1, Itajaí, jan./jun. 2001. Disponível em: https://siaiap32.univali.br/seer/index.php/rc/article/view/43. Acesso em: 10 abr. 2019.

SILVA, Andréia Ferreira da. Projetos em disputa na definição das políticas de formação de professores para a educação básica no Brasil (1987-2001). Curitiba: Appris, 2018.

SOUZA, Antônio Lisboa Leitão da. A conjuntura político-econômica e os desafios da educação no Brasil. In: FRANÇA, Magna; BARBOSA JÚNIOR, Walter Pinheiro (Orgs.). Políticas e práxis educativas. Natal: Editora Caule de Papiro, 2017.

SÜSSEKIND, M. L. As (im)possibilidades de uma base comum nacional. Revista E-Curriculum, São Paulo, v.2, n.3, p.1512-1529, out./dez., 2014. 